\title{
Takayasu's Arteritis with Isolated Pulmonary Artery Involvement in a Middle-Aged Asian Woman with Hepatitis B and Latent Tuberculosis Infection
}

\author{
Felix Liebscher $^{\mathrm{a}} \quad$ Thomas Pfammatter $^{\mathrm{b}} \quad$ Antonios Kolios $^{c}$ Matthias Greutmann ${ }^{\mathrm{d}}$ \\ Daniel Franzen ${ }^{\mathrm{a}}$ \\ ${ }^{a}$ Division of Pulmonology, ${ }^{b}$ Institute of Diagnostic and Interventional Radiology, ${ }^{c}$ Department of Immunology, and \\ ${ }^{\mathrm{d}}$ Division of Cardiology, University Hospital Zurich, Zurich, Switzerland
}

\section{Established Facts}

- The development of Takayasu's arteritis and infection with hepatitis B virus and Mycobacterium tuberculosis might be linked.

\section{Novel Insights}

- Isolated pulmonary artery involvement and its correlated symptoms can be the first and single signs of Takayasu's arteritis.

- Treatment of concomitant active hepatitis B might positively influence Takayasu's arteritis symptoms.

\section{Key Words}

Takayasu's arteritis • Vasculitis · Radiographic diagnosis · Pulmonary artery stenosis - Isolated pulmonary artery stenosis

\begin{abstract}
We report a rare case of Takayasu's arteritis with isolated pulmonary artery stenosis in the presence of active hepatitis $B$ and latent Mycobacterium tuberculosis infection in a middleaged Asian woman who initially presented with severe dyspnea on exertion and recurrent syncope, occasional burning chest pains, and fatigue. Therapy of the active hepatitis $B$ and latent $M$. tuberculosis infection together with a course of methotrexate led to a slight reversal of the symptoms, as angioplasty with or without stenting was not an option. The
\end{abstract}

\section{KARGER}

(c) 2017 S. Karger AG, Basel

E-Mail karger@karger.com

www.karger.com/res constellation described here hints at the possible link between hepatitis $B$ and $M$. tuberculosis infection and the development of Takayasu's arteritis. The case also supports the little evidence available indicating that treatment of active hepatitis B infection could positively influence the course of Takayasu's arteritis.

(c) 2017 S. Karger AG, Basel

\section{Introduction}

Takayasu's arteritis (TA) is a rare disease of unknown etiology [1]. It is characterized by an inflammatory arteritis classically involving the large vessels of Asian women in childbearing age, which results in stenosis of the affected arteries. The Chapel Hill Consensus Conference 
on the Nomenclature of Systemic Vasculitis defines it as "granulomatous inflammation of the aorta and its major branches" [2]. The subclavian artery is most commonly affected by TA. Involvement of the pulmonary arteries has been described in $10-50 \%$ of cases of TA, yet only about 15 cases of isolated involvement of the pulmonary arteries have been reported $[3,4]$, none of which appeared to be related to hepatitis. We report a case of isolated pulmonary artery involvement by TA in a middle-aged Asian woman concomitantly suffering from newly diagnosed active hepatitis B virus (HBV) and latent Mycobacterium tuberculosis infection.

\section{Case Report}

A 56-year-old woman of Asian descent was admitted because of severe dyspnea on exertion that had slowly progressed over the past 12 months. She had also experienced recurrent syncope on exertion and complained of occasional burning chest pain and vague fatigue. Her medical history was otherwise unremarkable except for a chronic lower back pain and mild polyneuropathy in both feet verified by clinical neurological examination.

On clinical examination, the patient was afebrile $\left(36.6^{\circ} \mathrm{C}\right)$, blood pressure and heart rate were normal (110/85 mm Hg and 96/ min, respectively) with no blood pressure difference between the arms. Auscultation of the lung was normal, while cardiac auscultation revealed a harsh $3 / 6$ systolic ejection murmur with radiation to the back. A diagnostic workup was initiated.

Echocardiography showed normal right ventricular systolic function with no evidence of pulmonary arterial hypertension. Pulmonary function testing revealed normal dynamic and static lung volumes and normal diffusion capacity for carbon monoxide after correction for ethnicity. However, on a bicycle stress test the patient managed a workload of $85 \%$ predicted when oxygen saturation decreased to $85 \%$ on ambient air. On chest computed tomography, the wall of the right pulmonary artery was thickened and surrounded by infiltrative mediastinal masses; there were no signs of a currently active tuberculosis (TB) infection. However, there were multiple subpleural retractile fibrotic lung scars, predominantly in the right upper and lower lobe. Chest magnetic resonance imaging showed severe tubular stenosis (minimal diameter $4 \mathrm{~mm}$ ) of the entire right branch of the pulmonary artery extending from its offset at the bifurcation of the main pulmonary artery into its main branches, which were occluded except for the descending artery and the lateral lower lobe segmental artery. Positron emission tomography with ${ }^{18} \mathrm{~F}$-fluorodeoxyglucose showed mild uptake by the vessel wall and the perivascular tissue of the right pulmonary artery (standardized uptake value $=4.9)($ Fig. $1 \mathrm{a}-\mathrm{c})$.

Laboratory tests revealed a high erythrocyte sedimentation rate (ESR, $81 \mathrm{~mm} / \mathrm{h})$, a mildly elevated C-reactive protein $(15-25 \mathrm{mg} / \mathrm{L}$, normal range $<5 \mathrm{mg} / \mathrm{L})$, an elevated rheumatoid factor $(50 \mathrm{U} / \mathrm{mL}$, normal range $<15 \mathrm{IU} / \mathrm{mL}$ ), and elevated aspartate aminotransferase $(74 \mathrm{U} / \mathrm{L})$ and alanine aminotransferase $(84 \mathrm{U} / \mathrm{L})$. Serologic testing revealed active chronic $\mathrm{HBV}$ infection (HBs antigen 8,038 U/L, $\mathrm{HBs}$ antibody negative, $\mathrm{HBc}$ antibodies positive, $\mathrm{HBe}$ antibody positive, HBV-DNA 65,000 U/mL); a Mantoux tuberculin skin test and an interferon $-\gamma$ release assay were positive. The patient had never received bacillus Calmette-Guérin vaccinations; a related scar on the left arm is not present. Repeated blood cultures were sterile, and repetitive sputum samplings were negative for mycobacteria. Differential blood count, urine analysis, serum protein electrophoresis, human immunodeficiency virus, Treponema pallidum particle agglutination assay, hepatitis $\mathrm{C}$ virus, antineutrophil cytoplasmic antibodies, antinuclear antibodies, anticitrullinated peptide antibodies, and anticentromere antibodies as well as complement for $\mathrm{C} 3 / \mathrm{C} 4$, cryoprecipitation, and antibodies to Histoplasma capsulatum were normal.

After endobronchial ultrasound-guided biopsy of the tissue surrounding the right pulmonary artery, there was no evidence of malignancy or infection with TB (Fig. 2). The presumptive diagnosis of TA was made, and a therapy with oral prednisone $1 \mathrm{mg}$ / $\mathrm{kg}$ was initiated and combined with azathioprine $100 \mathrm{mg} /$ day. Prior to that, in order to avoid reactivation of hepatitis or TB, a therapy was started with entecavir $0.5 \mathrm{mg}$ once daily and isoniazid 300 $\mathrm{mg}$ once daily. Due to the length of the stenosis and its associated branch occlusions, balloon angioplasty with or without stenting was not deemed beneficial in this case.

The immunosuppressive therapy initially led to a reduction of dyspnea, less frequent chest pain, and markedly reduced fatigue. Within 3 months, C-reactive protein and ESR were decreasing to normal levels, and the magnetic resonance angiography of the pulmonary arteries showed regression of the stenosis of the right pulmonary artery (Fig. 3). Prednisone was tapered and stopped during this time.

Within a few months, the disease relapsed under therapy with azathioprine, with newly aggravated chest pain, dyspnea, and an increase in ESR. At that point, chronic HBV infection was well controlled with less than 20 copies of viral DNA/mL, and transaminases had regressed to normal. High-dose methylprednisolone treatment ( 2.5 g over 3 days) was initiated, and methotrexate was started with rapid dose escalation to $20 \mathrm{mg}$ weekly, replacing azathioprine. This step-up in therapy lead to a stable pulmonary situation up to the present (18 months), with low ESR $(8 \mathrm{~mm} / \mathrm{h})$ and marked reduction of perivascular inflammation and fluorodeoxyglucose activity in imaging studies, while the degree of branch pulmonary artery stenosis remained unchanged.

\section{Discussion}

The case presented here is unusual for several reasons. Disease onset was rather late, as TA usually occurs in women between 10 and 40 years of age. Additionally, elevated rheumatoid factor is rare in TA and usually related to concomitant rheumatoid arthritis $[5,6]$. The patient presented has intermittent lower back pain but otherwise showed no signs of arthritis.

What makes the presented case unique is the isolated involvement of the pulmonary artery and the concomitant (latent) TB and HBV infections. It appears that isolated pulmonary artery involvement and its correlated symptoms can be the first and single signs of TA, 

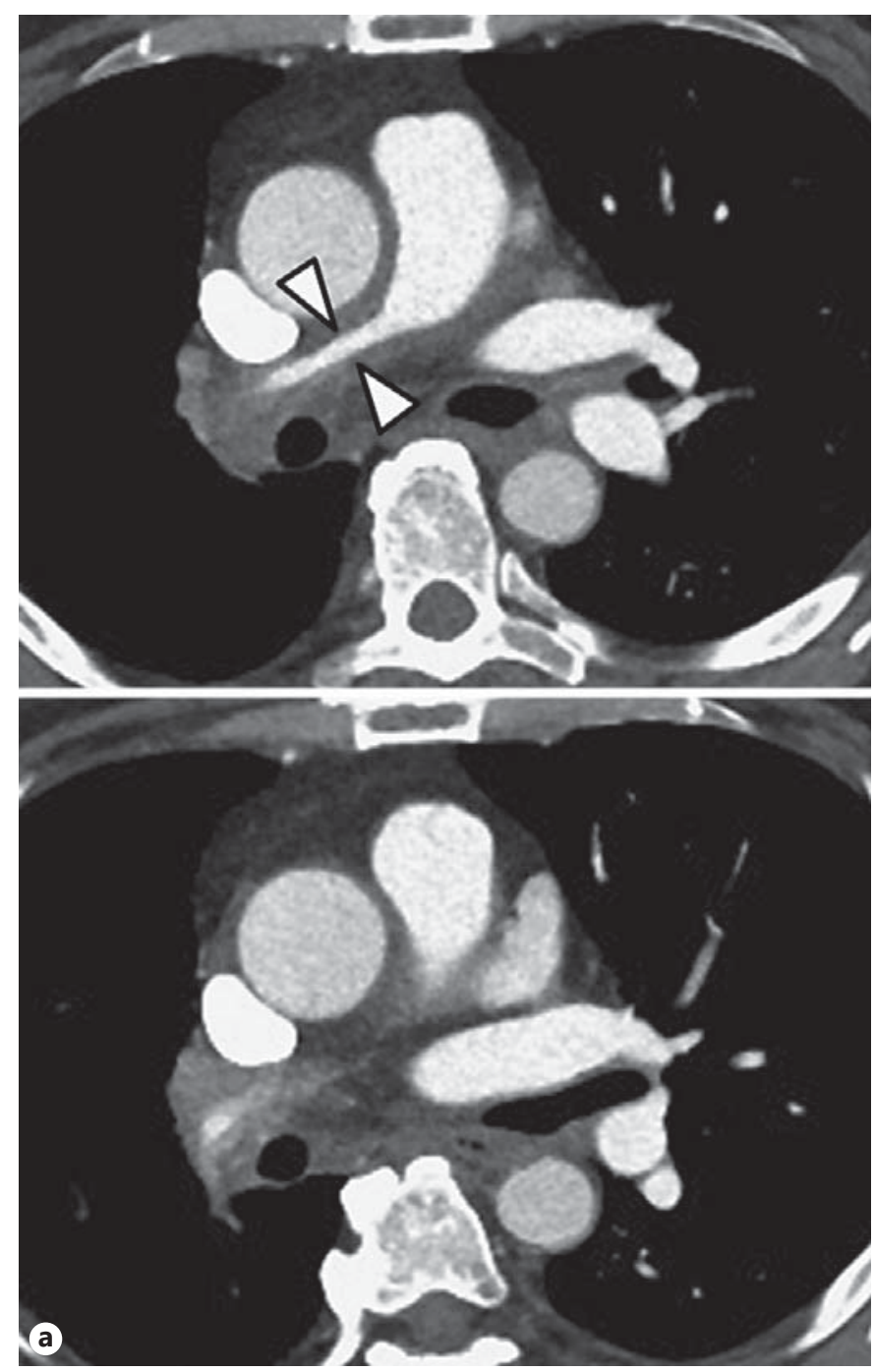

Fig. 1. a Contrast-enhanced computed tomography depicting a tubular stenosis of the right pulmonary artery (arrowheads) with wall thickening and haziness of the perivascular mediastinal fat. This aspect is consistent with a vasculitis. b At the initial ${ }^{18} \mathrm{~F}$-fluorodeoxyglucose positron emission tomography, there was just a

with only 15 cases reported so far [3], none of which were associated with concomitant TB and HBV infections.

We believe that the patient has latent TB infection on the basis of a positive interferon- $\gamma$ release assay, since tuberculin skin testing is not sufficient in patients with TA [7], even though the patient never had bacillus Calmette-
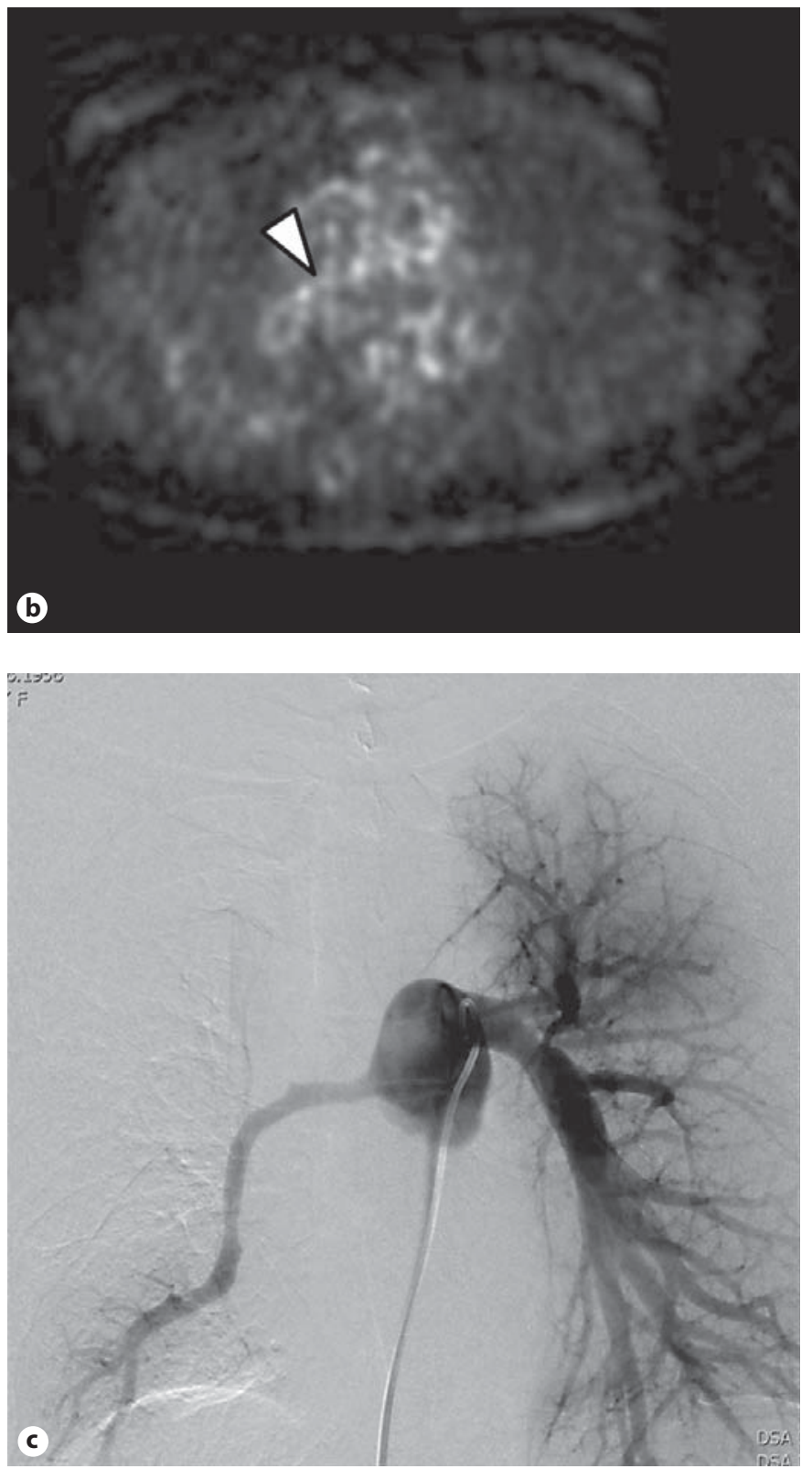

mildly increased metabolic activity around the right pulmonary artery (arrowhead). c Digital subtraction catheter pulmonary angiography showing disease extension beyond the hilum with just the lateral lower lobe segmental artery being patent.

Guérin vaccination and no postvaccination scar is present. Additionally, we found no evidence for active TB in biopsy samples or chest computed tomography. However, the latter revealed multiple subpleural retractile fibrotic lung scars, predominantly in the right upper and lower lobe, which are nonspecific, yet could be the result of a previous TB infection. 


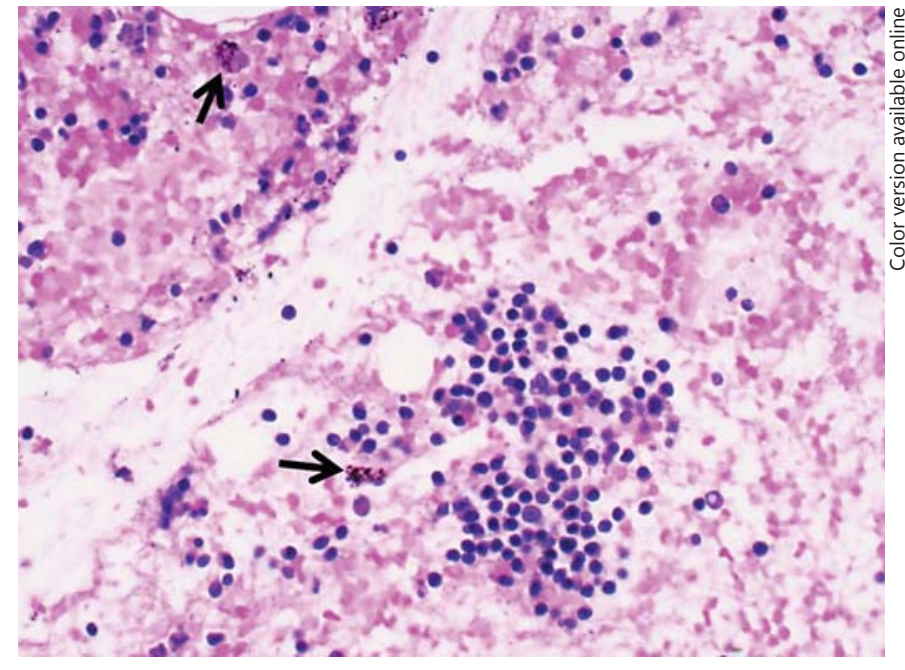

Fig. 2. Ultrasound-guided transbronchial fine-needle aspiration of the soft-tissue mass around the right pulmonary artery contains exclusively normal lymphatic tissue cells with anthracotic pigment containing histiocytes (arrows). HE stain of the cell block; original magnification $\times 400$.

Over the last decade, evidence has emerged which links TB infection to TA and suggests that a previous TB infection could induce TA [8-10], implying that there might be an autoimmune cross-reactivity facilitated by vascular peptides that mimic $M$. tuberculosis antigens [11]. In this context, it is not likely that TA symptoms could be affected by treatment of the latent TB infection, but it is possible that TB infection is a sufficient trigger to induce TA. Research investigating the link between TB infection and TA is currently ongoing.

There is relatively strong evidence supporting a link of polyarteritis nodosa with $\mathrm{HBV}$, hepatitis $\mathrm{C}$ virus, and human immunodeficiency virus infection, leading to a novel nomenclature for a subgroup of vasculitides called "vasculitis associated with probable cause" [2]. However, only a handful of reports exist that have found an association between TA and HBV infection. These suggest that TA symptoms could be influenced by treatment of the underlying HBV infection and bring up the concept of HBV surface antigen levels or HBV viremia being related to TA activity [12-14]. One report on the onset of TA after immunization with plasma-derived hepatitis B vaccine supports this idea [15]. The association, however, could also be explained by the fact that both HBV infection and TA are more common in Asians than in other ethnicities. The patient described in this report had HBV

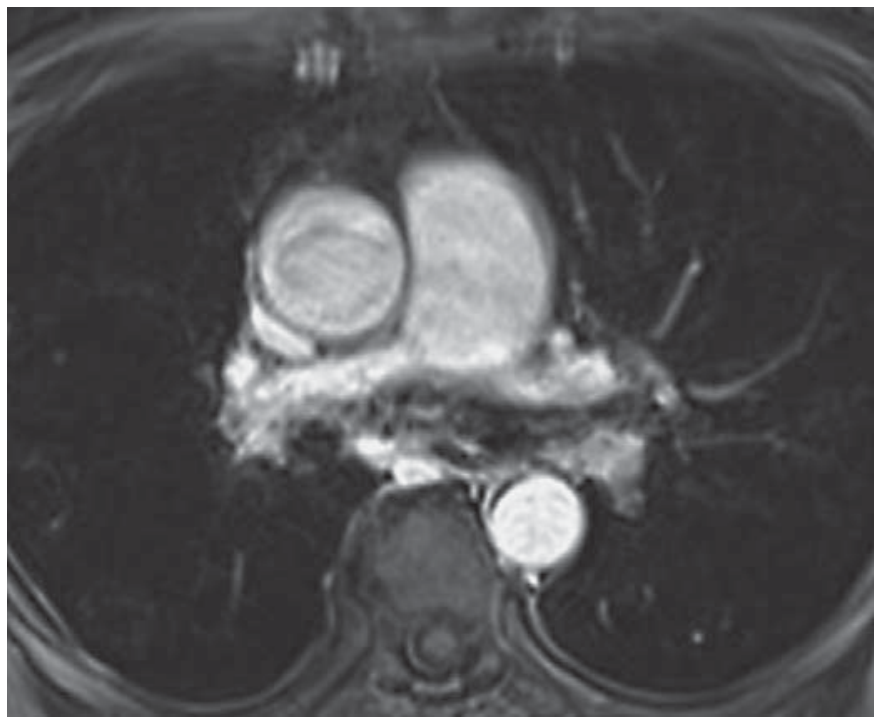

Fig. 3. After a 3-month anti-inflammatory treatment course (cortisone and azathioprine), follow-up contrast-enhanced magnetic resonance angiography showed slight stenosis reduction with persisting perivascular changes. The pulmonary branches remained occluded.

viremia at the time of disease onset, potentially supporting the hypothesis that highly active HBV infection may trigger TA.

Polyneuropathy can be a result of systemic vasculitis, which is also hypothesized as a trigger for TA. It would then typically involve the cervicobrachial plexus. On the other hand, polyneuropathy could also be associated with HBV infection but then would typically be associated with polyarteritis nodosa [16]. It is uncertain which of the 2 underlying diseases is responsible for the polyneuropathy in the presented case, but since we advocate an isolated involvement of the right pulmonary artery, the polyneuropathy is more likely to be due to the HBV infection or a nonrelated pathogenesis.

Along with an effectively controlled hepatitis B viral load and intensive immunotherapy with methotrexate, symptoms of TA markedly improved, while polyneuropathy showed little improvement. It is difficult to distinguish which of these 2 effects is responsible for symptom relief. Larger observational studies are needed to better define the potential triggering of TA by HBV infection.

This case report adds to the concept of a potential association of $\mathrm{HBV}$ infection and TB infection with the pathogenesis of TA. We advocate searching for HBV and TB infection in select patients with TA, as treatment of these conditions appears to improve the TA symptoms. 


\section{Acknowledgement}

We thank Prof. Beata Bode-Lesniewska from the Institute of Surgical Pathology at the University Hospital Zurich for providing the histology images.

\section{Financial Disclosure and Conflicts of Interest}

We have read and understood the Karger policy on the declaration of interests and declare that we (all authors) have no competing interests.

\section{References}

1 Arnaud L, Haroche J, Mathian A, et al: Pathogenesis of Takayasu's arteritis: a 2011 update. Autoimmun Rev 2011;11:61-67.

$>2$ Jennette JC, Falk RJ, Bacon PA, et al: 2012 revised International Chapel Hill Consensus Conference Nomenclature of Vasculitides. Arthritis Rheum 2013;65:1-11.

3 Toledano K, Guralnik L, Lorber A, et al: Pulmonary arteries involvement in Takayasu's arteritis: two cases and literature review. Semin Arthritis Rheum 2011;41:461-470.

$\checkmark 4$ Fukuda Y, Shirai K, Takamiya Y, et al: Isolated pulmonary arterial stenosis caused by Takayasu's arteritis in an elderly male. J Cardiol 2008;51:196-200.

5 Korkmaz C, Zubaroglu I, Kaya T, et al: Takayasu's arteritis associated with rheumatoid arthritis: a case report and review of the literature. Rheumatology (Oxford) 2001;40: 1420-1422.

6 Lupi-Herrera E, Sánches-Torres G, Marcushamer J, et al: Takayasu's arteritis. Clinical study of 107 cases. Am Heart J 1977;93:94103.
7 Karadag O, Aksu K, Sahin A, et al: Assessment of latent tuberculosis infection in Takayasu arteritis with tuberculin skin test and Quantiferon-TB Gold test. Rheumatol Int 2010;30: 1483-1487.

-8 Mwipatayi BP, Jeffery PC, Beningfield SJ, et al: Takayasu arteritis: clinical features and management: report of 272 cases. ANZ J Surg 2005;75:110-117.

-9 Kumar Chauhan S, Kumar Tripathy N, Sinha $\mathrm{N}$, et al: Cellular and humoral immune responses to mycobacterial heat shock protein-65 and its human homologue in Takayasu's arteritis. Clin Exp Immunol 2004;138: 547-553.

10 Soto ME, Del Carmen Ávila-Casado M, Huesca-Gómez C, et al: Detection of IS6110 and $H u p B$ gene sequences of Mycobacterium tuberculosis and bovis in the aortic tissue of patients with Takayasu's arteritis. BMC Infect Dis 2012;12:1-14.
-11 Castillo-Martínez D, Amezcua-Guerra LM: Self-reactivity against stress-induced cell molecules: the missing link between Takayasu's arteritis and tuberculosis? Med Hypotheses 2012;78:485-488.

12 Ozenirler S, Gokalp-Yasar D, Demirag M, et al: Takayasu's arthritis associated with chronic hepatitis B. Acta Gastroenterol Belg 2007; 70:306-307.

13 Zaas A, Scheel P, Venbrux A, et al: Large artery vasculitis following recombinant hepatitis B vaccination: 2 cases. J Rheumatol 2001; 28:1116-1120.

14 Prokhorova MV, Zverev KV, Krel PE: Takayasu's disease associated with liver cirrhosis in a patient with HBs-antigenemia (in Russian). Ter Arkh 1992;64:103-104.

-15 Castresana-Isla CJ, Herrera-Martinez G, Vega-Molina J: Erythema nodosum and Takayasu's arteritis after immunization with plasma derived hepatitis $\mathrm{B}$ vaccine. J Rheumatol 1993;20:1417-1418.

16 Finsterer J: Systemic and non-systemic vasculitis affecting the peripheral nerves. Acta Neurol Belg 2009; 109:100-113. 